\title{
FUNCTIONAL ASPECTS OF THE EVOLUTION OF FROG TONGUES
}

\author{
Philip J. Regai \\ Museum of Natural History, The University of Minnesota, Minneapolis 55455 \\ AND \\ CARL Gans \\ Division of Biological Sciences, The University of Michigan, Ann Arbor 48104
}

Received July 24, 1975

Revised January 22, 1976

Amphibians are remarkable in having a tongue that is propelled from the mouth, to impact on, adhere to, and pull prey into the buccal cavity. Although sometimes listed as a characteristic defining the class, it is only among certain salamanders and frogs that the tongue appears to be flipped out rather than moved by incremental control. Its action is thus analogous to that of the projectile tongue of chameleons (Gnanamuthu, 1930; Gans, $1967)$, rather than to the merely extensible tongue of anteaters, some birds, and snakes. The mechanism of the tongue of frogs, which is propelled by the rotation of "soft" tissues about the mandibular symphysis, is fundamentally distinct from that of the tongue of salamanders, which is hurled anteriorly by a forward shift of the hyobranchial skeleton (Regal, 1966; Özeti and Wake, 1969; Lombard and Wake, 1976; Larson and Guthrie, 1976).

The tongue has been used in the 19th Century and through the present as a "taxonomic character" in the classification of frogs (cf. Lynch, 1973). However, the structure, function and evolution of this complex lingual system has received but minimal attention. Perhaps symptomatic of such neglect is that an obscure but beautiful study of the ontogeny and morphology of the tongue and its intrinsic muscles in 42 species of frogs (MagimelPelonnier, 1924) has not been brought to light in any subsequent treatise on the frogs (Noble, 1931; Werner, 1930; Reeder, 1964; Blair, 1972; Vial, 1973) and, in- deed, in the major handbook of vertebrate anatomy (Nishi, 1938).

The mechanical basis of tongue projection has long been discussed and debated, mainly for the advanced genera Rana and Bufo (Dugès, 1827, 1835; Hartog, 1901; Gaupp, 1901; Barclay, 1942; Gnanamuthu, 1933; Böker, 1937). Recently its mechanism has been explained anew (Tatarinov, 1951; Gans, 1961, 1962), though experimental confirmation is still lacking. It is commonly assumed that the condition of Rana or Bufo can be generalized at least for anurans belonging to "nonarchaic" or "modern" taxonomic groups, such as the Ranidae, Bufonidae, Hylidae, Leptodactylidae, and Rhacophoridae, in which the tongue is attached in front with a "free flap posteriorly." The "archaic" taxonomic groups, the Ascaphidae (here both Liopelma and Ascaphus but see Savage, 1973), Discoglossidae, Pipidae, and Rhinophrynidae, are supposed to differ, having noneversile, posteriorly attached, or even completely margined tongues when present. The function of such tongues remains unstudied.

We propose here that statements such as "tongue present" or "tongue absent" and even "tongue with free flap posteriorly," do not necessarily define shared character states, but conceal critical biomechanical complexity and evolutionary parallelisms.

It is not our intention here to present a comprehensive monograph on frog tongue structure and function. We document (1) 


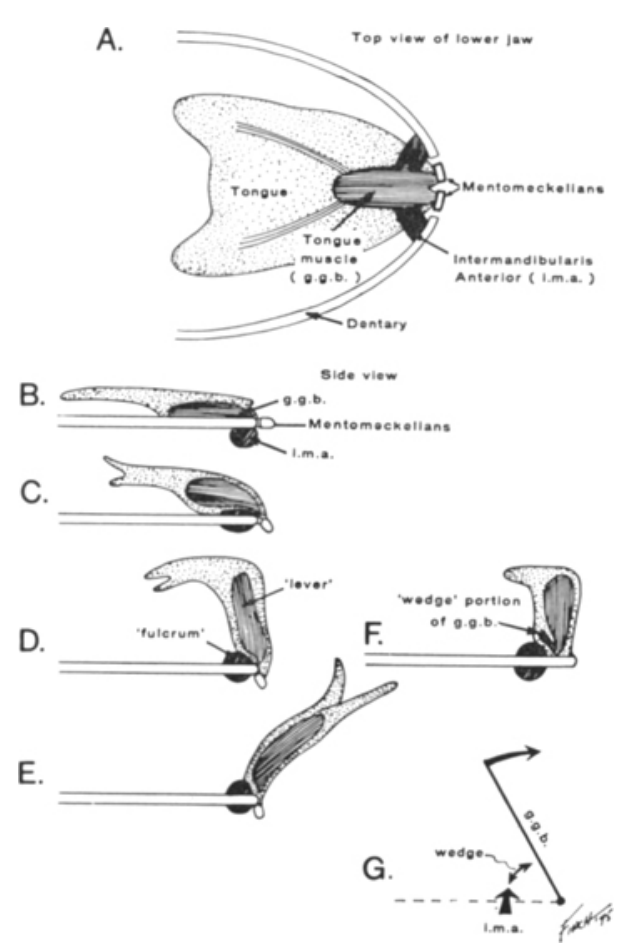

FIG. 1. A-E. Model of tongue propulsion in a frog such as Rana. (The retractor muscles are omitted.) At rest (A, B) the tongue muscle lies in the plane of the mandible. As the flip starts (C) the tongue muscle (ggb-genioglossus basalis) contracts and stiffens to form a lever. At the same time the intermandibularis anterior (ima) contracts to form a rising fulcrum. The insertion of the tongue muscle on the mentomeckelian elements is dropped below the level of the rising fulcrum, an action possible because of flexible areas in the lower jaw between the symphysial elements and the dentary (D). The soft, posterior portions of the tongue are thus hurled forward (E). F, G. In a frog such as Ceratophrys the mechanical components are arranged so that rotational acceleration may be imparted to the soft tissue of the tongue even though the symphysis is inflexible. Contraction of the wings or flaplike portions of the ggb would cause bulges that would tend to force the lever and fulcrum apart by coupling the mechanical action of a "wedge" to the system.

that the "archaic" frogs show a diversity of structural and functional patterns. We further document by a few examples (2) that the tongues of certain "advanced" frogs differ fundamentally from one another in structure and presumably in func- tion (3). To promote discussion and to give further impetus to functional studies, we will present speculative sequences of functional transition: comments on the possible evolution of grades or levels of organization of propulsive tongues and comments on possible parallelisms.

As some of these grades conceivably have been achieved by reversion from more advanced levels (perhaps resulting from specialization for distinct feeding modes), we expressly avoid assigning the observed conditions to a true phylogenetic scheme. We have, furthermore, made no attempt to question the homology of the diverse buccal and tongue muscles. All glossal fascicles are routinely called "genioglossal" when they originate from the vicinity of the symphysis, or "hyoglossal" when they originate from the hyoid elements. These topographical criteria for homology remain to be tested by more conventional ones (e.g., studies of ontogeny and innervation).

\section{Descriptions of Frog Tongues}

\section{Previously Recognized Diversity and Function}

Gans (1961, 1962) proposed a pattern of tongue propulsion for the condition in Rana, an advanced frog (Fig. 1, A-E). In essence, the basal genioglossus represents a rod-shaped mass of muscle fibers stacked transversely to the body axis and encased in a connective tissue envelope that attaches to the mandibular symphysis and runs the length of the tongue (Fig. 2 ). Contraction turns the flaccid mass into a rigid rod or lever. Rapid depression of the attachment of the genioglossus with the mandibular symphysis rotates the short end of the lever (the genioglossus) over a rising fulcrum (the contracted intermandibularis anterior); this provides maximum linear acceleration of the distal genioglossal tip. The soft tissues of the lingual tip are carried along by the end of the genioglossal rod and expend their kinetic energy in further extension (Fig. 


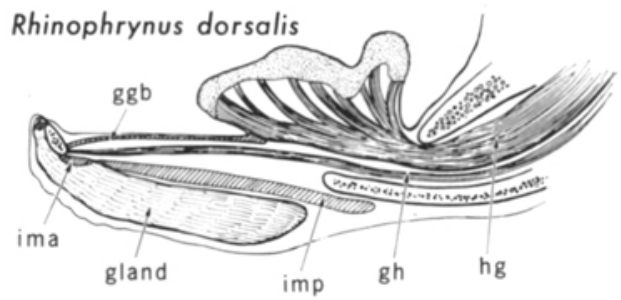

Cyclorana dahli
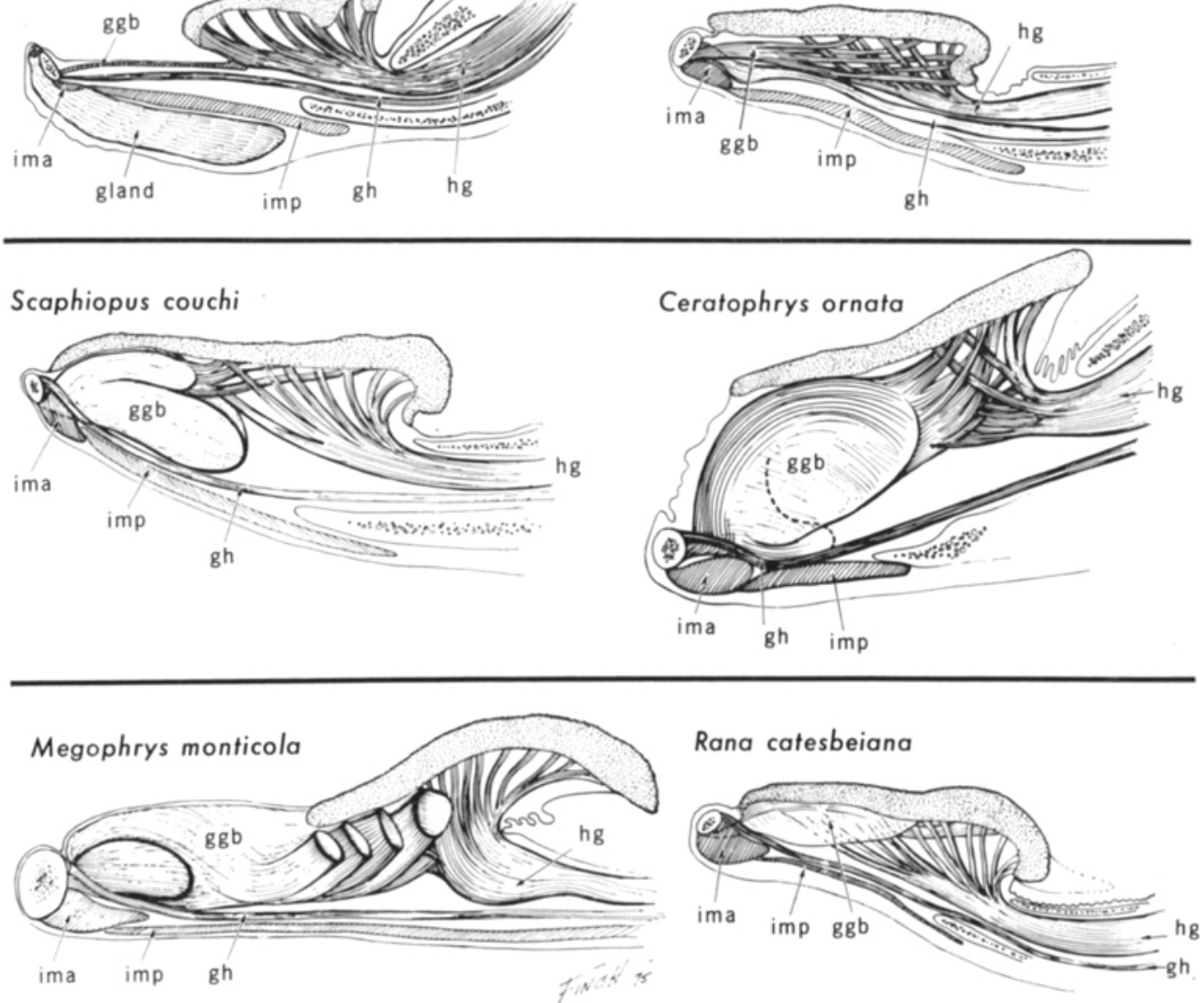

FIc. 2. Sagittal and parasagittal sections through the tongues of representative Anura. Though diagrammatic these were drawn with the aid of a camera lucida. The heads point to the left. Rhinophrynus: Note massive development of the retractor muscle $(\mathrm{hg})$ and poor development of the ggb or any other potential protractors. Cyclorana: This drawing also serves to represent the condition in Ascaphus and Bombina. Note particularly the diffuse organization of the protractor muscles (ggb) which are effective in protracting the tongue, but which are not organized so as to form a lever system. The interdigitating insertion of the protractor and retractor fibers into the tongue pad is characteristic of the tongues of all the following frogs. Scaphiopus: It is notable that the "wedgelike" portion of the ggb is relatively huge. Diffuse fascicles diverge lateral to the midline as the dorsal portions of this muscle, and are compact primarily in the small area where they join along the midline. Ceratophrys: The dorsal portion of the ggb is relatively huge along the midline. The dorsal portion of the muscle branches into loose fascicles as it turns laterally to interdigitate with fascicles of the retractor (hg) and insert into the tongue pad. Note that the basal "wings" or "wedge" of the ggb are primarily lateral to the midline, hence the right flap illustrated is indicated by a dashed line since it would be located deep to the primary plane in view. Megophrys: The sagittal section illustrated passes only through a left lateral wing of the ggb and the stout bundles of its left posterior portion as they branch beneath the tongue pad, apparently offering structural support. Thus, one sees primarily the surface of the ggb and the five severed lateral portions (indicated by heavy lines). Rana: The compact form of the ggb is particularly noteworthy. Lateral fascicles from the genioglossus can be seen beneath the hg. $\mathrm{ggb}=$ genioglossus basalis $; \mathrm{gh}=$ geniohyoid $; \mathrm{hg}=$ hyoglossal $; \mathrm{ima}=$ intermandibularis anterior $; \mathrm{imp}=$ intermandibularis posterior. (The nature of the structure labeled "gland" was not actually investigated.) 
1). The basic action is not dissimilar to those of the onager and trebuchet, ancient and medieval catapult devices used in warfare. Of course, the force with which an onager propels an object is stored in the elastic deformation of the wooden beam, whereas force used to propel the frog tongue for the most part derives immediately from the contraction of the genioglossus muscle.

Among primitive frogs the aquatic Pipidae lack tongues and show consequent differences in the muscles of the buccal floor (Chaine, 1900).

The primitive discoglossid (and ascaphid) frogs have, "a round disclike tongue which adheres by nearly all of its base to the floor of the mouth" and it has been assumed that, "it can not be extended when its owner takes food" (e.g., Cochran, 1961).

The primitive and peculiar Mexican frog, Rhinophrynus, has a distinctive tongue that is said to be, "free anteriorly and apparently protrusible in mammal rather than in frog fashion. A close parallel occurs in the African bufonid Werneria" (Noble, 1931).

Some "advanced" or "nonarchaic" frogs of southeast Asia and the IndoAustralian Archipelago are said to have peculiar tongues, deviating from the standard pattern of "attached in front, with free flap behind." For example, "Colpoglossus is specialized in that the posterior part of the tongue is tightly bound to the middle of the floor of the mouth. This makes the posterior edges of the tongue curl over to form a shallow pocket. In Glyphoglossus among the Cacopinae and in many other subfamilies of brevicipids a parallel modification has occurred except that in these the whole median portion of the tongue is usually tightly fixed, producing a crease for the greater part of its length" (Noble, 1931).

No motion analysis, much less electromyography, has been performed on these species. A functional framework for future study of salientian tongues is obvi- ously needed. We begin with a general discussion of the buccal system. Then some tongue conditions that differ from Rana are described and interpreted as a basis for evolutionary constructions.

\section{Organization and Functions of the Buccal System}

The frog's lower jaw is framed by the narrow, rod-shaped, curved mandibles, the tips of which may join in a loose or tight symphysis, or may be loosely connected as in Rana by a distinct pair of medial ossifications, the mentomeckelian bones (symphysials). (Bufo and Rana will serve as a basis for discussing common advanced frogs.) The semicircular gap between the mandibles is spanned by a wide, variously angled sheet of posterior intermandibular muscles. These intermandibulars lie immediately beneath the skin and may run from side to side, interdigitate medially, or may be interrupted by a median aponeurosis. More anteriorly is the much thicker bundle of the anterior intermandibular, which attaches along the mandibles just posterior to the symphysial tips. Deep to the intermandibulars pass the geniohyoids, that run from the symphysial region of the mandibles to the hyoids (Corsy, 1933). Contraction of these muscle layers will lift the buccal floor, simultaneously rotating the mandibles inward. The extent of ventral excursion of the buccal floor may be limited by anterior projection of the pectoral girdle.

The tongue muscles lie dorsal to this floor. In general, one or more genioglossal series originate from the symphysial region and enter the tongue. The most anterior components of this system are sometimes associated with the anterior part of the geniohyoid. More dorsally, posteriorly and laterally the series subdivides and fans out.

The hyoglossal mass (tongue retractors) proceeds anteriorly from the hyoid; the fascicles travelling as a bundle and only separating near the base as they enter the tongue. The fascicles of several tongue 
muscles generally interdigitate in their course and attach in a staggered pattern. The base of the tongue, through which they pass, of ten contains one or more lymphatic sinuses, and even when strict sinuses do not occur, one finds the crossing fibers attached only loosely to each other so that they are clearly discrete as soon as the tissue is even slightly teased and the intervening connective tissues stretched.

The dorsal surface of the tongue is normally covered by a more or less clearlydefined, thickly-folded mucous glandular pad. Whether or not it has free edges, there is likely to be considerable folding of the surrounding mucous membranes, documenting their capacity to stretch during excursions of the tongue pad. Indeed the apparent extent of free "edge" or "flap" is often misleading. (MagimelPelonnier, 1924, comments on the extent of individual variation in preserved specimens.)

The above structural pattern, which is subject to numerous variations, incorporates the basis for several biological roles.

1. Pumping.-The buccal cavity serves as a power source for the pulse pumping method of breathing. Simultaneous contractions of the intermandibular and geniohyoid muscles lift the floor and this drives air into the lungs (de Jongh and Gans, 1969; Martin and Gans, 1972).

2. Narial closure.-In some frogs contraction of the anterior intermandibular muscle closes the nostrils (Gaupp, 1901; Gans, 1974), thus sealing the bucco-pulmonary cavities and permitting a pressure rise during pulse pumping, as well as during the filling of vocal sacs and air storage during vocalization (Martin and Gans, 1972). Dorsal shift of the movable symphysis acts on the premaxilla and through this peculiar linkage the nares are closed. It is unclear how the nostrils are closed in the minority of frogs that lack mentomeckelian bones or symphysial motility. Could the smooth muscles mentioned by
Bruner (1902; cf. Noble, 1931) take over this function?

3. Prey manipulation.-The tongue serves as the primary manipulative organ for shifting food within the buccal cavity. Selective movements of the tongue pad, perhaps against the ratchet sometimes furnished by the vomerine teeth, shift food objects. Pressure of the bony jaws, the hyoid, the eyes, and the intermandibular sheet also may be involved in subduing prey and in forcing it toward the esophagus.

4. Capture.-In eversion of the tongue its sticky dorsal surface rotates so that it faces downward around prey items. Retraction pulls the entrapped object into the buccal cavity.

Any functional scheme has to take into account the need to fulfill the possibly conflicting demands of these biological roles.

\section{The Discoglossid-Ascaphid Level of Tongue Organization}

Virtually all criteria suggest that the Discoglossidae and Ascaphidae are quite primitive (Kluge and Farris, 1959; Estes and Reig, 1973; Lynch, 1973; Sokal, 1975). The tongue system is simple. The tongue of Bombina, for example, appears poorly differentiated. Only the anterior portion is well-defined, and there are no posterior free edges in the specimens examined. The surrounding mucous tissues are loose and the anterior lingual surface is covered with minute papillae that may increase the tongue's frictional purchase upon food items. The vomerine teeth lie opposed to the papillose surface and may assist in holding and manipulating objects in the mouth, similar to their function in salamanders (Regal, 1966), and they may simultaneously abrade the prey to facilitate taste discrimination as with Rana (Francis, 1961).

Dissection of the tongue reveals two main series of diffuse muscles. A first series spreads posteriorly and radially from the vicinity of the mandibular symphysis 


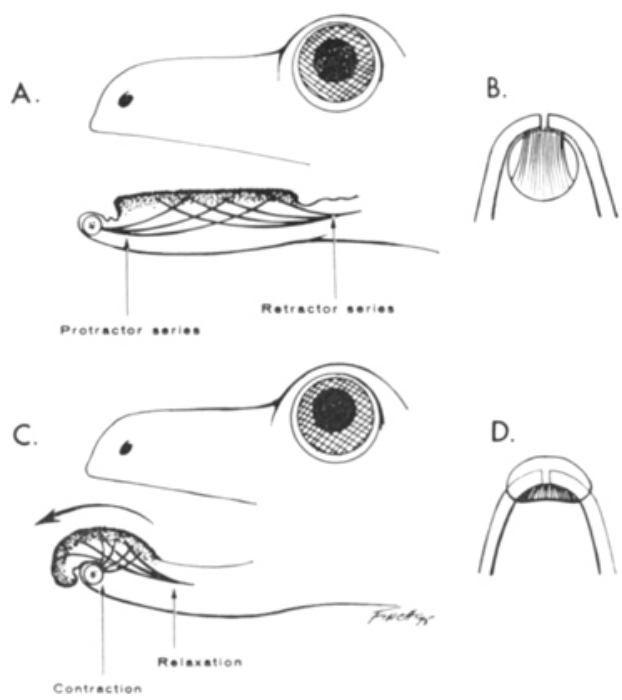

FIG. 3. Structural elements in the tongue of Bombina, Ascaphus and Cyclorana consist primarily of an interdigitating protractor and a retractor series of muscles as they insert ventrally into the tongue pad (shown here is a highly diagrammatic sketch). A. Lateral view. B. Dorsal view. The tongue is shown at rest with only the protractor fibers indicated. C. Our movies show that the tongue can be projected from the mouth and rolled over the edge of the lower jaw. This would be accomplished by contraction of the genioglossus while the retractor series (hg) is relaxed. D. Dorsal view of same condition as $C$.

as it branches into fascicles that insert widely into the ventral side of the thickened tongue pad. The other and more elongated series runs anteriorly from the vicinity of the hyobranchial apparatus and branches into a number of fascicles and insert on the ventral side of the tongue, interspersing with the first group (as in the "nonarchaic" Cyclorana, Fig. 2).

The simplest functional interpretation is that contraction of the posteriorly branching genioglossal series would pull the tongue forward (Fig. 3). A prey item already in the mouth would then be stabilized as it is pushed against the marginal and palatal teeth. Contractions of the anteriorly branching hyoglossal series of muscles, with the tongue in a forward position, would draw the tongue (and attached food items) backwards over the posteriorly directed teeth. Such a discoglossid tongue might seem to be effective primarily in the manipulation of food items. Thus it represents a condition comparable to the putative second level of functional specialization in salamanders (Regal, 1966).

Salamanders such as Ambystoma not only have this manipulative capacity but can also protrude the tongue slightly to capture and ingest prey (Regal, 1966; Severtsov, 1971; Larson and Guthrie, 1976). Such a capacity is important in the evolution of more advanced tongue types, as this function exposes simple structures and behaviors to the influence of further selection.

Analysis of our motion pictures of Bombina orientalis lunging and biting at houseflies shows a slight and rapid but unmistakable protrusion of the tongue. In effect, the tongue rolls out over the front of the lower jaw, forming an adhesive leading edge to which the fly adheres, and on which the fly is then carried into the mouth. The discoglossid tongue is consequently capable of some protrusion and serves in food capture (Fig. 3 ).

The tongue mechanism of Ascaphus appears to be basically similar to that of Bombina. The genioglossal fascicles are diverse with large and small bundles inserting across the deep surface of the tongue pad. The hyoglossal muscles pass anteriorly in a broad band deep to the tongue that abruptly splits into fascicles and distributes attachments among those of the genioglossus. Consequently we are pleased to see the report of Larson and Guthrie (1976) that the tongue of $A s$ caphus, too, is protruded in feeding. Both sets of observations allow us to speculate that further morphological specialization among frogs might have resulted from a remodeling of the tongue at this simple level of organization to increase the effectiveness of the food catching function and behavior. Bombina and Ascaphus might be assumed to retain a prototype structure for terrestrial frogs, from which more advanced frog tongues might be derived. 


\section{The Tongue of Rhinophrynus}

Rhinophrynus dorsalis is a peculiar burrowing toad from Mexico and Central America. It is toothless, has a very small head, tiny eyes, a pipidlike tadpole (most recently, Sokol, 1975), and a loud and unmistakable voice. The symphysial region of its lower jaw is anteroposteriorly flattened. Most recent studies rank it as a primitive, "archaic" frog (Kluge and Farris, 1969; Lynch, 1973). Noble (1931) popularized the idea that Rhinophrynus had a tongue like a mammal, free in front rather than behind, and this wording has been preserved in the literature. Actually the tongue surface is merely highly folded and in some specimens the folding does not cause it to appear as described by Noble.

The head of Rhinophrynus is peculiar. First of all the pectoral girdle lies very far anteriorly, completely overlapping the hyoid and reaching the level of the lingual base (because the head is so small). Thick hyoglossal fascicles enter the tongue and spread out dorsally (Fig. 2). In contrast, there is a relatively thin sheet of genioglossal muscle that passes to the lingual base but does not appear to enter the tongue itself (also noted by Magimel-Pelonnier, 1924). In dorsal view, the posterior edge of the tongue often forms a crescent of thick and curved lateral arms. The mucous membranes here cover lateral branches of the hyoglossals that provide flexible connections to the hyoid plate. The plate itself is broadly suspended by muscles and appears to be capable of significant antero-posterial shifts.

There can be no question but that the thin sheet of genioglossal muscle cannot effect a shift of the tongue forward past the symphysis. If this toad really licks up termites and ants (Freytag, 1967), it can only do so when an anterior shift of the hyoid carries the tongue with it. At the very least this should permit the pressing of the tongue against the smooth internal edges of the mouth so that the central portion could protrude from the aperture (Fig. 4). The intrinsic lingual muscles would then serve to orient the tongue so that its dorsal surface faces anteriorly (out of the mouth) and later to rotate it backwards with the prey. The flattened external edge of the symphysial surface may be interpreted as an adaptation that permits the animal to get close to tunnel openings. Its thickened skin and curious underlying layer of fatty connective tissue may aid it to resist the stings and bites of worker ants and termites as it "licks" them up.

It is interesting that the condition in Rhinophrynus is analogous to that in some salamanders in that the tongue is protruded by movements of the hyoid. Of course the details of structure and function are in no way the same, but we emphasize that the condition in Rhinophrynus is apparently unique for frogs. The tongue here is best interpreted as a radically independent experiment in tongue evolution.

\section{The Tongue of Ceratophrys}

The horned frogs, genus Ceratophrys, inhabitants of South America, have enormous, heavily ossified skulls and a large mouth and stronger jaws and teeth than do most salientians. They are well-known for their powerful bite, and take large prey such as other frogs, toads, lizards, snakes and small mammals. Ceratophrys attracted our attention because it lacks mentomeckelian elements and is in a "nonarchaic" frog group (leptodactylid-bufonid affinities). The symphysis of the lower jaw is fused; however, a heavy triangular anterior intermandibular muscle is present. No separate mentomeckelians are notable in adults (however, a cleared and stained juvenile retains what is possibly an ossification center at the tip of Meckel's cartilage). These frogs are unusual in having undivided teeth (Lynch, 1971, and pers. obs., contra Parsons and Williams, 1962), heavily ossified skulls, and neural spines on the vertebrae recalling the lower Per- 
mian "frog" vertebra described by Vaughn (1965).

The tongue of Ceratophrys (Fig. 2) is distinctly different from those described previously. A stout geniohyoid lies immediately deep to the intermandibulars, and attaches medially near the dorsal edge of the mandible. The massive genioglossal bundles attach immediately lateral but also somewhat ventral to it on each side. Two stout cylindrical muscle masses with pointed ends run each to one lingual tip and here provide further fascicles to the base of the tongue pad. The short, generally transverse, internal fibers attach to the connective tissue sheath of the masses, but this lacks posterior attachments so that the lingual tissues should be able to slide over them with little friction. Each genioglossal mass also includes a distinct wedge-shaped basal flap that extends as a lateral wing, to the mandibular edge. The hyoglossal muscles insert in three separate series of fascicles, respectively into the medial and the two lateral portions of the tongue from their origin on the posteroventral aspect of the hyoid plate. The fascicles are well-defined, though joined by loose connective tissues rather than placed into a sinus.

It is noteworthy that since there are no separate mentomeckelians the system cannot function as in Rana.

The short fibers of the several sets of genioglossal muscles, attached only to their encapsulating connective tissue sheath, should not alone induce much motion, but rather, upon contraction may provide a stiffened framework for the two wings of the tongue. Contraction of the posterior intermandibular would shift the anterior i.m. dorsad and contraction of the latter would cause it to thicken so that its dorsal surface would rise further. The overlying geniohyoids would consequently be lifted and would in their contraction transmit all three sets of incremental movements to the base of the genioglossals. Contraction of the basal wedges or wings would induce a further significant upward shift (Fig. 1, F, G) and with the stiffening and thickening of the main masses impart significant rotational acceleration to these "rods." As a lymphatic sinus occupies the lingual base and the soft tissues of the lingual pad are attached mainly at the genioglossal tips, the rotation would cause them to move centrifugally and to describe the path more of the shot than of the sling. The entrained kinetic energy would stretch the hyoglossal attachments. Contraction of the hyoglossals repositions and shifts the lingual surface ventrad. Attachment of the hyoglossals far posteriorly on the hyoid surface would provide the maximum fiber length and with this, maximum absolute shortening.

Dissection alone does not reveal if the tongue of Ceratophrys is truly a "flipping tongue" or produces only a rapid, but controlled shift of the soft tissues past the buccal edge. Extrapolation from structure tends to suggest the former. The length of the genioglossal rods, significantly greater than in Rana, and the addition of basal wings may compensate for the inflexible symphysis (perhaps reflecting a specialization toward the immobilization of large prey, or representing a primitive character state).

\section{The Tongue of Megophrys}

Megophrys monticola is a pelobatid frog of Malaysia, the tadpoles of which have umbrella-like mouths with which to suspend themselves from the water's surface. The adult frogs seem to be scavengers of the forest floor. The genus. is interesting in being among the most primitive of the "nonarchaic" frog groups. The tongue, however, is far from simple. In fact the genioglossal shows one of the most beautifully complex internal arrangements that we have seen in vertebrate muscle (Fig. 2).

The tongue is shaped like a Ping-Pong paddle with the long cylindrical "handle". bulging beneath smooth but folded mucous tissues and reaching from the man- 
dibular symphysis to the flat, circular, papillate tongue pad, the "paddle" lying more posteriorly. Multiple folds of the buccal mucosa cross the "handle" suggesting remarkable motility. The edges of the "paddle," but not of the "handle," are deeply undercut.

The posterior intermandibular muscles are thin, but continuous, and are arranged in several layers. The geniohyoids are very broad, radiating from the anterior symphysis and then passing posteriorly in parallel over the medial two-thirds of the buccal floor. The anterior i.m. is thick and lies interspersed between the posterior i.m. and geniohyoid. The tongue pad receives as usual, the genioglossal and hyoglossal muscles, the former being by far the stouter. The genioglossal mass is curiously modified. It starts anteriorly, from the symphysial region, just dorsal to the thickened anterior intermandibular. Posteriorly it does not simply diffuse into the tongue tissues but actually seems to form a stout, supporting structural framework for the "paddle" with series of symmetrical lateral branches.

The genioglossus is unusually complex and the following description based upon dissections only, will ultimately have to be amplified on the basis of serial sections. The anteroventral base appears as a delta wing-shaped mass generally of short anteroposterior fibers. All of these fibers insert on the capsular connective tissues and the capsule lacks posterior connections. Longer fibers originate more dorsally and swing over the ventral mass to pass along the dorsal surface as a longitudinal series of bundles towards the center of the tongue pad. They form a solid and most complexly organized rod as some of the fibers spiral clockwise and others counterclockwise down the sides and thus surround the bundles of the central core. Fascicles first descend mid-ventrally then pass laterally along the bottom and again ascend the sides of the rod at angles to the former. Thus a series of stout fascicles enters the tongue sequentially (it is unclear whether their fibers continue from the symphysis or terminate as insertions on the connective tissues of the main rod).

The hyoglossal muscles are much narrower and represent a sparser and more standard pattern. Starting from the ventral surface of the hyoid plate they curve loosely to insert across the ventral surface of the tongue pad.

While the described arrangement is seemingly distinct from that observed in any other species, its function may again be characterized in terms of the basic lever systems previously discussed (Fig. 1). Contraction of the intermandibulars, geniohyoid, and basal genioglossal muscles would tend to rotate the more dorsal "rod" of genioglossal muscles around the symphysial region. The contraction of the central longitudinal fibers of the dorsal portion of the genioglossal muscle should cause the mass to become rigid, rather than to shorten significantly, as deformation will be inhibited by the spirals of the tightly enclosing superficial genioglossal layers. The muscular wrapping may restrain the swelling of the interior bundles and provide the lingual paddle with a stout handle anteriorly. Not only does the tongue appear as a Ping-Pong paddle, it may act like one.

\section{The Tongue of Bufo}

The cosmopolitan and advanced genus $B$ ufo includes the common toads. We have only examined the tongues of two species, Bufo woodhousii and Bufo marinus, of significantly different sizes. Their tongues superficially remind one of the "typical" frog tongue seen in Rana in that the pad starts near the symphysis, and extends posteriorly as a divided rather than as a single flap that has wide free edges laterally and posteriorly.

Internally, the system differs fundamentally from that seen in Rana. The difference is not in the arrangment of intermandibulars and geniohyoids or in the flexible connection of the symphysis. The difference relates to the nature of the 
genioglossal fibers. These fibers are arranged in a ventrally placed wedge encompassed by some surrounding connective tissues. In contrast to the situation in Rana, these fibers do not run transversely or even obliquely, but essentially anteroposteriorly. More dorsal to them lies a series of even longer fibers, the longest of which penetrate into the wings of the tongue.

The hyoglossal muscles are of typical arrangement. Their insertion intersperses across the lingual surface. The hyoglossal and genioglossal muscles pass through the sinus at the base of the tongue.

Published (and unpublished) photographs document the way in which the toad's tongue unrolls during projection (e.g., Barclay, 1942). These views show clearly that the ventral base (presumably the basal genioglossi) rotates first, passing well beyond the symphysis and dragging the tongue pad with it. The wedging and pulling action of the genioglossal system provides the propulsion, further enhanced by the depression of the mandibular symphysis which accentuates the rotation. The soft tissues of the lingual pad are carried along with the rod's tip; they trail or drag after it. After the rod has achieved its greatest excursion these soft tissues continue to travel due to their inertia. One can see the pad first stretching and then rotating so that its surface turns ventrally before impacting on possible prey. Retraction occurs by the paired bundles of the hyoglossus. Excellent photographs by Schubert (1974) document this phase.

The toad's tongue would seem to incorporate a potential for asymmetric action not seen in Rana. No experiments have yet explored the question of control, though it is of obvious interest, and not only for questions of phylogeny.

\section{Some Unexpected Grades of Tongue Complexity}

The tongue was also examined in various leptodactylids and pelobatids with results that do not seem at first to match the presumed status of these animals based on other characteristics (Lynch, 1971). In Cyclorana dahli (UMMZ 65250Leptodactylidae, or Pelodryadidae in some arrangements) the tongue mechanism is relatively simple: essentially the condition in Bombina (Fig. 2). In Telmatobius marmoratus (UMMZ 68179-Leptodactylidae) the posterior edge does have a fold or flap but the muscles are relatively simple, much again as in the discoglossid level of organization. In contrast, Neobatrachus pelobatoides (UMMZ 1619-Leptodactylidae, or Nyobatrachidae) features a very large anterior mandibular and two strong well organized genioglossi basales with short fibers positioned at an angle to their length and with subdivisions that radiate outward from the attachment to the symphysial region.

The condition in Scaphiophus (Fig. 2) is strikingly dissimilar to the other pelobatid examined, Megophrys. The dorsal "lever" portion of the genioglossus is extremely bifurcated and the ventral "wedge" portion is relatively huge.

Several other species show similarly unexpected results. The above forms are mentioned here only to document that frogs deserve a detailed survey for this character on the generic, and indeed the specific, level.

\section{Drscussion}

\section{Implications for Phylogenetic Studies}

The preceding cases lead to a number of immediate conclusions. First, they suggest that even those tongues that are least specialized and lack complex intrinsic musculature may be rolled out over the jaw edge and thus pick up food. Consequently, the lingual condition of the archaic species needs to be re-evaluated, both anatomically and functionally.

As interesting are the multiple cases of diversity within the "modern" species, as well as the fact that these do not fit simply into the classification schemes of recent authors. For example, Lynch (1971) 
suggests that Megophrys is one of the least advanced of the nonarchaic pelobatids, yet its tongue seems to us extremely complex. In contrast, Telmatobius marmoratus and Cyclorana dahli, primitive members of the supposedly more advanced "Leptodactylidae," have what we consider to be extremely simple tongues, essentially similar to that of Bombina. Other "leptodactylids," Ceratophrys, and Neobatrachus have what would seem to be advanced tongues, incorporating enormous, organized genioglossi basales.

The diversity of structural conditions among the relatively few species thus far sampled only suggests that tongue structure and function may be useful in shedding some light on questions of salientian phylogeny. A limiting factor in considering the classification and phylogeny of the Anura has been a paucity of characters useful in analysis (e.g., Starrett, 1968, 1973).

As important, the occurrence of simple and advanced tongue propulsion conditions within each of several families suggests strongly that the advanced tongues may be the result of several lines of parallel evolution. Thus, it is unwise to continue designating shared character states for frog tongues, pending careful studies which consider the functional and evolutionary questions raised in this report.

Among archaic frogs the condition in Rhinophrynus is of particular interest. If our interpretation is correct, we have here a tongue moved not by its intrinsic muscles but by a shift of the hyoid (Fig. 4). It does represent a fundamentally different pattern from that seen in any other frog, a pattern that, despite its analogy to certain salamanders, may hardly be considered ancestral. Consequently, there is evidence that the capacity to pick up diverse prey by means of an eversible tongue may have evolved independently a number of times among both the archaic and the modern frogs.

It is an interesting question why, despite parallelism within each group, the
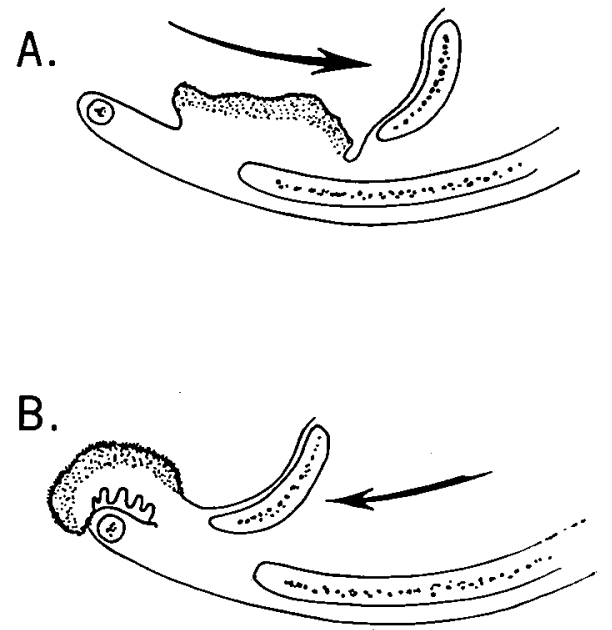

FIG. 4. The tongue of Rhinophrynus lacks an obvious protractor series and must work on a different principle from that in other frogs. We propose that the hyolaryngeal apparatus is extended anteriorly and thus pushes the mass of tissue and sinus fluid out of the mouth. The shape and movements are conceivably controlled by the hg (not shown here). A. Schematic sagittal section through the lower jaw, tongue relaxed. Also indicated in this section are dentary (left) and portions through the hyolaryngeal apparatus and pelvic elements (right). B. Tongue as it might appear when protracted by an anterior shift of the hyolaryngeal apparatus to the left.

tongues of frogs and salamanders followed characteristically different evolutionary paths. Could it be that the branchial skeleton of ancestral frogs had early become involved in sound production and so was unavailable for extensive remodeling in connection with feeding? In this case the voiceless condition in Liopelma and Ascaphus would represent a secondary loss. Reduction in, or loss of, the sound producing apparatus has recently been discussed for several species of bufonids (Martin, 1972). However, the reasons for possible loss of sound production in the Ascaphidae are not obvious. Ascaphus now lives in swift and often noisy mountain streams and it is possible that reduction of bouyancy led to reduced lungs and that voicelessness may well be the consequence. Liopelma is reported to produce 
shrill chirping distress sounds, even though it lacks a mating call (Stephenson and Stephenson, 1957). More must be learned about the ecology, behavior and morphology of ascaphids before one can draw the conclusion that they are all voiceless or that voicelessness is primary.

Until further evidence becomes available we may consider as one possibility that the voice became important early in anuran evolution before selective pressures made a manipulative buccal floor critical.

\section{Transitions Between Levels of Organization: Functional Considerations}

With the above in mind it is plausible to speculate regarding the functional aspects of evolutionary shifts.

(1). Fully aquatic frogs presumably do not need a proper tongue with a friction surface. Buccal manipulation of food particles in water is possible (involving inertial feeding of suspended objects) utilizing the pumping effects of the buccal musculature and the abrasive action of pharyngeal and more anterior teeth when present (e.g., Regal, 1966). These considerations would, incidentally, partially explain the tonguelessness of pipids if the condition in the Aglossa is secondary.

(2). With any shift to air breathing and terrestrial habitats, mucous membranes would become more common. Nonaqautic food items are necessarily utilized and water pumping cannot be used to manipulate food items. Feeding in terrestrial niches must have created major pressures selecting for new methods of food manipulation and capture. The remnants of the old branchial musculature became modified for moving a tongue pad in manipulation, and the intermaxillary gland and associated structures became developed along with terrestrial chemosensory capacity.

(3). Frogs, whether they arose in the Triassic or Jurassic confronted a diversity of abundant terrestrial arthropods. A variety of methods for picking up small terres- trial arthropods would have been of advantage, and their development often may well have been a condition for successful survival.

The earliest frogs may have lunged at prey (Gans and Parsons, 1966). Contact of any moist mucous membrane would have promoted adhesion of small dry arthropod exoskeletons. The temporary protrusion of loose buccal membranes at the end of a lunge probably had a sufficient selective advantage so that looseness was elaborated in a series of small functional steps ultimately leading to controlled protrusion.

(4). Initially protrusion may have involved a series of muscles (genioglossal) radiating from the symphysial region and diffusely attaching across the ventral surface of the buccal lining. Contraction would reduce the area over which this skin was stretched, thus folding it and causing it to bunch at or over the mandibular edge. There would be a selective advantage to a thickening of the pad's center as this would restrict bending initially to the unthickened anterior edge and then cause the intrinsic resistance of the sheet to roll it over the edge. A thickened buccal membrane would incorporate further advantage if it involved the development of papillae and hypertrophy of the mucous glands of the lingual surface. Their contents would be squeezed out upon impact, wetting the prey and increasing adhesion. This is essentially the condition in ascaphids, Bombina, Cyclorana and Telmatobius.

(5). Eversion would be enhanced further by sinus (or bursa) formation and the accumulation of tissue fluids ventral to the tongue and between the muscle fibers. Tissue fluids between the muscular fascicles would achieve an initial advantage of reducing intermuscular resistance during deformations of the floor. The fluid contents would be restrained from ventral displacement by the simultaneous contraction of the sheet of intermandibu- 
lar and geniohyoid muscles; contraction of the posterior genioglossal fibers of the tongue would then shift this liquid and enhance the anterior bulge of the buccal membrane by a hydraulic effect.

(6). The tongue apparatus might also be protruded by an anterior shift of its hyoid base (cf. Trewavas, 1933 for hyoid variants). With this, tongue excursion would presumably be limited by the extent of hyoid excursion. This may be a major constraint on the system of tongue protrusion apparently utilized by Rhinophrynus.

(7). A "higher" structural grade would be achieved as the genioglossal muscles became more organized, and the fascicles fused into heavy bundles along the midline and into the sides of the tongue. (It is unclear how much bilaterality reflects asymmetric control of protrusion.) Stiffening of genioglossals thus tightly bound during contraction would provide the tongue with a temporary "skeletal support," improving its manipulative ability as well as protrusive and prey capture functions. It is possible that manipulation (or possibly even closure of the internal nares!) may have been the primary function. We lack evidence for such points.

(8). What is clear is that a bundle of tightly associated muscle fibers can turn rigid on contraction and may even form a stiff rod. A repositioning of its attachments so that contraction of associated muscles rotates the rod, can induce centrifugal forces on the connected soft tissues. In simplest terms, this rotational action facilitates the shift of soft tissues toward the mandibular edge and subsequently beyond this.

(9). Several types of intrinsic muscle arrangements would improve the mechanical effectiveness of such rods. Laterally positioned short fibers within a wrapping of dense connective tissues more clearly define it and induce minimal shortening of the rod during contraction. Spiral wrappings, such as those seen in Megophrys, also represent a configuration that may turn a flaccid muscular assemblage into a rigid structure without undue shortening upon contraction.

(10). Other extrinsic as well as intrinsic arrangements increase the mechanical advantage of forces and displacements in the system. Contraction of the posterior intermandibular, of a thickened anterior intermandibular and of the geniohyoids would tend to lift the rod. Dorsal fibers would have a lifting effect, further rotating the rod about its insertion. Separation of a short fibered flap or flaps of genioglossus basalis ventral to the rod, such as in Scaphiopus, Megophrys, Ceratophrys and $B u f o$, incorporates the potential for additional angular acceleration. All of these modifications lift the body of the rod. Simultaneous depression of the origin of the muscular rod would induce a force couple and produce a multiplier effect. Such depression could potentially involve medial rotation of the curved mandibles, and depression of separate (mentomeckelian) elements of their tips. All increase the couple imposed on the rod and with this increase the tip's angular acceleration. The loose soft tissues thus achieve sufficient kinetic energy to stretch out and bypass the rod as its tip rotates beyond the symphysial level.

(11). Fluids entrained in the basal lymphatic sinuses would shift outward during this portion of the movement. Such outward change of mass increases the rotational momentum and adds energy to the distal tissues. The inward pull on the soft tissues at the beginning of lingual rotation furthermore reduces the initial rotational inertia and permits buildup of angular velocity during the critical phase.

\section{A Hypothetical Evolutionary Framework}

Adult protofrogs may have been aquatic (e.g., Nevo, 1968) and used water movements to manipulate prey; or perhaps they were terrestrial, mainly utilizing relatively large prey items that would have to be pushed into the mouth by movements of the forelegs or by pressing the prey against the substrate. 
Once protofrogs entered an adaptive zone in which prey manipulation was of particular advantage, the frictional characteristics of the floor of the mouth would have been subject to further selection. $\mathrm{Ma}$ nipulative and protrusible tongues would extend the size range of food items available to such animals (Regal, 1966): the resultant selective advantage would reflect the frog's capacity to feed on small as well as on large prey. The conditions seen in living terrestrial frogs could then have arisen in two ways. If the buccal floor and hyolaryngeal apparatus of the first frog was like that of modern pipids and permitted dorsoventral pumping displacements, selection could have acted to increase the range of anteroposterior hyoid movements, which would bunch the tissues of the floor of the mouth. Differentiation of a dorsal series of retractor fibers would have permitted improved control over the shape of the bunched tongue and over the range of movements possible in retraction; this seems to be the condition in Rhinophrynus. We assume that this system incorporated intrinsic limitations as the range of the tongue may be constrained by the range and direction of hyoid movement.

Alternatively (or subsequently) some of the fibers of the branchial musculature, or of the floor of the mouth might have migrated directly to the positions seen in Bombina or Ascaphus with a posteriorly branching series for forward displacement of mucous membranes and an anteriorly branching series for retraction. Differentiation of the tissues of the floor of the mouth into a friction surface would accompany the most elementary manipulative system.

Greater protrusion of the tongue than seen in Bombina could be accomplished by laterally constraining the space into which the tissue may be extruded. Thus, instead of forming a broad margin of extruded tissue, the tongue would be protruded as a more nearly hemispherical organ: narrower, but longer. Drawing in of the lat- eral margins of the tongue could be accomplished by fusion of fascicles of the genioglossi along some portion of the midline. At this point we could begin to refer to a well-defined, organized, $m$. genioglossus rather than a diffuse series of muscle fibers. Once assembled into compact muscle bundles, contraction of this series would also begin to have the potential to form a rigid rod as described for Rana.

The transition from a rigid rod to a lever arm is major. As long as the genioglossal series only produces forward motion, it matters little whether the fibers are compact or diffuse. Utilization of rigidity to produce an upward (rotational) as well as a forward vector would seem to require additional elements in the functional system.

The transverse mandibular musculature could serve as a fulcrum if the insertion of the genioglossus were placed ventral to it, or if the mandibular symphysis were temporarily shifted ventrally. The lever-fulcrum system of Rana may have seen its origin in young frogs with incompletely ossified skeletons (de Jongh, 1968) where the symphysis would be depressed at the start of tongue action. Selection may have acted to delay throughout ontogeny, ossification in the region of the mandibular symphysis. Once the genioglossus had begun to take on a more compact form and became rigid during contraction, selection for a lever-fulcrum system might have occurred rapidly, first in the deformation of the mandibles of newly transformed frogs and then by the retention of juvenile features in adults. The system produced is the classical condition in Rana.

The above hypothesis does not predict the condition in Ceratophrys. The genioglossus of Ceratophrys could produce an upward as well as an anterior movement of the tongue even though the tips of the mandibles are well ossified. This motion is apparently possible because of the "legs" or "wings" formed ventrally by the genioglossus basalis. Bulging of this section could serve essentially to wedge the stiff- 
ened rod of the genioglossus apart from the rigid, supporting intermandibularis anterior, thus rotating the lever about its fixed origin at the mandibular tips (Fig. 1, $F$, G.). The size of this portion of the genioglossus basalis suggests that this system plays a variously major role in producing rotational acceleration in a variety of anurans. In Scaphiopus the basal "wedge" is strikingly large (with an important function in prey manipulation?). In $\mathrm{Mego-}$ phrys and Ceratophrys it is a modest but distinctive element in the system. In Bufo the "wedge" is smaller still but could play a significant role in protraction. In Hypopachus, Breviceps, Glyphoglossus, Phrynomerus, and Rana (all microhylid-ranid genera) we consider the "wedge" to be absent.

One may speculate that the functional sequence could have proceeded by at least two paths toward advanced anuran tongues. Along the first path depression of the mentomeckelians evolved early and rotation of the lever took place as the symphysial insertion dropped and rotated about the rising fulcrum. The second path saw evolution of symphysial depression relatively recently. While this second path at first seems unnecessarily complicated, one can conceive of structural or developmental constraints, or perhaps a predatory way of life that required stout mandibular tips early in ontogeny. The ventral portion of the genioglossus might initially have thickened, perhaps to press the tongue dorsally during prey manipulation, thus starting the basis for further selection. As a by-product, the dorsal portion pulled the tongue pad up as well as forward. This slight rotational component of movement would help to carry the tongue over the edge of the jaw during a lunge. In some forms such as Scaphiopus the basal wedge is huge, suggesting that manipulative functions may be quite important (or the system may represent an early and as yet unrefined mechanism for rotational acceleration of the tongue).

Following the incipient stages of rota- tional acceleration, this function may have been further modified by fascicular arrangements that would stiffen those portions of the genioglossus dorsal to the wedge. Once stiffened the soft tissues would not simply slide up and forward; as the genioglossus became progressively longer and more rigid in phylogeny they would be rapidly lifted and rotated; they would function as a lever arm. Such a system, coupling the swelling anterior intermandibularis and rising geniohyoid to a "wedge" and a "lever," could produce a functional system analogous to that in Rana.

Still, many frogs such as Bufo seem to have both a ventral wedge and depressible mentomeckelians. This is to be expected since depressible symphysials would add further to the acceleration of the lingual tip. A shift from a reliance on large active prey to exploitation of smaller prey would, for example, reduce the advantage of a rigid symphysis and the projectile function of the tongue could be improved by reconstruction of the symphysial region. This may have happened many times as a more versatile tongue allowed the exploitation of small prey and as competition with advanced lizards, birds and mammals placed high premiums on efficiency over the last 200 million years.

The above speculations may be confirmed or rejected as the much needed detailed functional studies incorporating electromyography, and comprehensive comparative descriptions, accumulate. We hope that the present report elucidates an adequate variety of biomechanical principles and hypotheses, and of possible evolutionary ramifications to facilitate such studies.

\section{SUMMARY}

The tongue has long been used as a taxonomic character for frogs, yet its mechanics and evolution have not been understood. We document that there are many functional and structural tongue patterns among living anurans. The prin- 
ciples on which the various types of tongues can function are outlined. Possible paths and causes of evolutionary transition between levels of organization are discussed. It is likely that there has been considerable parallel evolution of tongue types in anurans within both archaic and advanced families.

\section{Acknowledgments}

We would like to thank the following persons for offering comments on the manuscript at various stages in its preparation: W. R. Heyer, H. J. de Jongh, R. A. Nussbaum, T. S. Parsons, H. I. Rosenberg, H. B. Tordoff and D. Wake. We thank H. Marx (Field Museum-Chicago) and R. A. Nussbaum (Museum of Zoology, University of Michigan) for permission to dissect specimens, and Dr. C. Schubert for allowing us to examine photographs of tongue retraction in Bufo. We are grateful for support of the National Science Foundation (BMS 71-01380).

\section{Literature Cited}

BARCLAY, O. R. 1942. Feeding of the common toad. Nature 150:376.

BLAIR, W. F. (ed.) 1972. Evolution of the genus Bufo. Univ. Texas Press, Austin and London.

BökER, H. 1937. Einführung in die vergleichende biologische Anatomie der Wirbeltiere, II. Biologische Anatomie der Ernährung. Gustav Fischer, Jena.

BRUNER, H. L. 1902. The smooth facial muscles of Anura and Salamandrina, a contribution to the anatomy and physiology of the respiratory mechanism of the amphibians. Morph. Jahrb. 29:317-359.

Chaine, T. 1900. Anatomie comparée de certains muscles sus-hyoidiens. Thèse Fac. Sci. Paris, (6 Dec. 1900). (A) 374 (1041):1-210. L. Daniel, Lillie; Bull. Sci. (Paris) 35:1-210.

Cochran, D. M. 1961. Living amphibians of the world. Doubleday and Co., Inc. N.Y.

Corsx, F. 1933. Evolution de l'appareil hyobranchial. P. Ciarfa, Marseille.

DE JoNGH, H. J. 1968. Functional morphology of the jaw apparatus of larval and metamorphosing Rana temporaria L. Netherl. J. Zool. 18:1-103.

DE Jongh, H. J., ANd C. Gans. 1969. On the mechanism of respiration in the bullfrog, Rana catesbeiana: A reassessment. J. Morph. 1927:259-290.
DuGÈs, A. 1827. Recherches anatomiques et physiologiques sur la déglutition dans les Reptiles. Ann. Sci. Nat. 12:337-395.

- 1835. Recherches sur l'ostéologie et la myologie des Batraciens à leurs différents ages. [Ann. Sci., Nat. I. (Zool.) 1834 p. 365-372]; Paris, Mémoires des savans etrangers (1935) 6:1-216 (Académie Royale des Sciences).

Estes, R., AND O. A. ReIG. 1973. The early fossil record of frogs. A review of the evidence. In J. L. Vial (ed.), Evolutionary biology of the anurans. U. Missouri Press, pp. 11-63.

FrancIs, E. T. B. 1961. The sources and nature of salivary secretions in Amphibia. Proc. Zool. Soc. London. 136:453-478.

FreytaG, G. E. 1967. Amphibia. In Urania Tierreich: Fische, Lurche, Kriechtiere. UraniaVerlag. Leipzig, Jena, Berlin.

Gans, C. 1961. A bullfrog and its prey. A look at the bio-mechanics of jumping. Natural History (New York) 70(2):26-37.

- 1962. The tongue protrusion mechanism in Rana catesbeiana. (abst.). Amer. Zool. 2(4):524.

- 1967. The chamaeleon. Natural History (New York) 76(4):52-59.

- 1974. Biomechanics. J. B. Lippincott Co., Philadelphia and Toronto.

Gans, C., AND T. S. Parsons. 1966. On the origin of the jumping mechanisms in frogs. Evolution 20:92-99.

GaUpp, E. 1901. Ueber den Muskelmechanismus bei den Bewegungen der Froschzunge. Anat. Anz. 19:385-396.

GnanamutHu, C. P. 1930. The anatomy and mechanism of the tongue of Chamaeleon carcaratus (Merrem). Proc. Zool. Soc. London. 1:467-486.

- 1933. The anatomy of the tongue of Rana hexadactyla. Rec. Indian Mus., 35:125-144.

Hartoc, M. 1901. The mechanism of the protrusion of the tongue of the Anura. Preliminary note. Ann. Mag. Nat. Hist. 7:501-503. (Trans. from Compt. Rend. Acad. Sci. 4 March 1901.)

Kluge, A. G., AND J. S. Farris. 1969. Quantitative phyletics and the evolution of anurans. Syst. Zool. 18:1-32.

LARson, J. H., JR., AND D. J. Guthrie. 1976. The feeding system of terrestrial tiger salamanders (Ambystoma tigrinum melanostictum Baird). J. Morph. (in press).

Lombard, E., AND D. B. Wake. 1976. Tongue evolution in the lungless salamanders, family Plethodontidae. I. Introduction, theory, and a general model of dynamics. J. Morph. (in press).

Lynch, J. D. 1971. Evolutionary relationships, osteology, and zoogeography of leptodactylid frogs. U. Kansas Nat. Hist. Pub. 53:1-238.

- 1973. The transition from Archaic to ad- 
vanced frogs. In J. L. Vial (ed.), Evolutionary biology of the anurans. U. Missouri Press, p. 133-182.

Magimel-Pelonnier, O. 1924. La langue des amphibiens. Thèse, Faculté des Sciences de Paris. A. Saugnac and E. Provillard, Bordeaux. $260 \mathrm{p}$.

Martin, W. F. 1972. Evolution of vocalization in the genus Bufo. In W. F. Blair (ed.), Evolution in the genus Bufo. U. Texas Press, p. 279-309.

Martin, W. F., and C. Gans. 1972. Muscular control of the vocal tract during release signaling in the toad Bufo valliceps. J. Morph. 137:1-27.

Nevo, E. 1968. Pipid frogs from the early Cretaceous of Israel and pipid evolution. Bull. Mus. Comp. Zool. (Harvard) 136:255-318.

Nishi, S. 1938. Muskeln des Kopfes. Parietale Muskulatur. In L. Bolk, E. Göppert, E. Kallius, W. Lubosch (eds.), Handbuch der vergleichenden Anatomie der Wirbeltiere. Urban and Schwarzenberg, Berlin and Vienna, p. 447-466.

Noble, G. K. 1931. The biology of the Amphibia. McGraw-Hill Book Co., New York.

ÖzETI, N. AND D. B. WAKE. 1969. The morphology and evolution of the tongue and associated structures in salamanders and newts (family Salamandridae). Copeia 1969:91-123.

Parsons, T. S., and E. E. Williams. 1962. The teeth of Amphibia and their relation to amphibian phylogeny. J. Morph. 110:375-389.

ReEder, W. G. 1964. The digestive system. In J. A. Moore (ed.), Physiology of the Amphibia. Academic Press, New York and London, p. 99-149.

Regal, P. 1966. Feeding specializations and the classification of terrestrial salamanders. Evolution 20:392-407.

SAvAGE, J. M. 1973. The geographic distribution of frogs: patterns and predictions. In J. L.
Vial (ed.), Evolutionary biology of the anurans. U. Missouri Press, p. 351-445.

SchUBert, C. 1974. Behäbiger Riese mit schneller Zunge. Tier 14(1):30-31 + back cover.

Severtsov, A. A. 1961. On the mechanism of tongue protraction in anuran amphibians. [In Russian]. Doklady Akad. Nauk SSR. 140: 256-259.

- 1971. The mechanism of food capture in tailed amphibians. [In Russian]. Doklady Akad Nauk SSSR, 197:729-731.

Sokor, O. M. 1975. The phylogeny of anuran larvae: a new look. Copeia 1975:1-23.

Starrett, P. H. 1968. The phylogenetic significance of the jaw musculature in anuran amphibians. Diss. Univ. Michigan. Ann Arbor.

- 1973. Evolutionary patterns in larval morphology. In J. L. Vial (ed.), Evolutionary biology of the anurans. Univ. Missouri Press, p. 251-271.

Stephenson, E. M., and N. G. Stephenson. 1957. Field observations on the New Zealand frog, Leiopelma Fitzinger. Trans. Roy. Soc. New Zealand 84. p. 867-882.

Tatarivov, L.P. 1951. Tongue movement mechanism in tailless Amphibia [In Russian]. Doklady Akad. Nauk SSSR. 116:707-709, Translation 916-918.

TRewavas, E. 1933. The hyoid and larynx of the Anura. Phil. Trans. Roy. Soc. London. (B) 222:401-527.

VAUGHN, P. 1965. Frog-like vertebrae from the lower Permian of southeastern Utah. Los Angeles Co. Mus. Cont. Sci. 87:1-18.

VIAL, J. L. (ed). 1973. Evolutionary Biology of the Anurans, Univ. Missouri Press, Columbia.

WerNer, F. 1930. Allgemeine Einleitung in die Naturgeschichte der Amphibia. In T. Krumbach (ed.), Handbuch der Zoologie. Walter DeGruyter \& Co., Berlin und Leipzig, Vol. 6 (part 2): pp. 1-92. 